10.2478/genst-2018-0007

\title{
IMPACT OF UNDERGRADUATE LANGUAGE AND GENDER RESEARCH: CHALLENGES AND REFLECTIONS IN THE CONTEXT OF QATAR
}

\author{
IRENE THEODOROPOULOU \\ Qatar University \\ Department of English Literature and Linguistics \\ PO Box 2713, Doha, State of Qatar \\ irene.theodoropoulou@qu.edu.qa
}

\begin{abstract}
The paper aims at raising female students' awareness about sexism in language and designing and applying sociocultural linguistic interventions in Qatar. Contributing to the nascent feminist research tradition in this relatively new and rapidly up-and-coming country, it presents a tangible pedagogical proposal from the context of tertiary education. At the same time, in terms of its contribution to genderrelated sociolinguistic theory this project can be seen as an attempt to offer a suggestion on how to theorise the positionality of sociolinguistic professionals in relation to issues and contexts they address.
\end{abstract}

Keywords: empowerment, feminism, impact, Qatar, representation, sexism.

\section{Introduction}

As an empirically-based field of enquiry, sociolinguistics has to do not only with the relationship between society and language but also, and perhaps most importantly, with the ways through which we can use our sociolinguistic findings to improve people's sociolinguistic lives. What I mean by "sociolinguistic lives" is that the uses of language(s), including, of course, doing research on language and reflecting upon our methods and analytical tools, should be aiming at securing equality, justice and freedom within the boundaries of a given society; in other words, the "real world applications" (Lawson \& Sayers 2016a:9) of sociolinguistic research need to be foregrounded, in order for the field to become known outside the confines of academia. Such a shift towards becoming more proactive in terms of what our contribution as sociolinguists to the 
society is or should be is reflected in recent scholarship (e.g. chapters in Lawson \& Sayers 2016b; Wee 2016).

This more practical aspect of sociolinguistics, which is basically the answer to the "so what?" or "why bothering doing sociolinguistics?" question, became obvious to me, when I started teaching sociolinguistics in a context, which, was totally unfamiliar to me until 2010: the State of Qatar. This is an absolute monarchical country in the Middle East, which, nonetheless, is considered liberal compared to its neighbours Saudi Arabia and Iran, owing to its progressive former Emir, HH Sheikh Hamad bin Khalifa Al Thani. The Father Emir himself has prioritised education as one of the country's most important domains, through which the sustainability of the country and its citizens can be secured. This is evident in Qatar Vision 2030, as found in the following link:

http://www.gsdp.gov.qa/portal/page/portal/gsdp_en/qatar_national_vision/qnv_2030_document/ QNV2030_English_v2.pdf (23/2/2018). On p. 20, there is a description of the education priorities of the country.

Such prioritization of education runs spectacularly in contrast with many countries in the Western world, primarily European countries and the United States, many of which are currently facing financial recession and as a result they have to curtail their budget every year. One of the fields that has suffered extensively because of these cuts is education and subsequent research activities. On the contrary, Qatar spends every year more money on research-related initiatives via its respective universities, Qatar University and the universities of Qatar Foundation, and its flagship in research, Qatar National Research Fund. More specifically, in the country's 2016 budget, "health, education and infrastructure accounted for the largest share of the 2016 budget at 91.9 billion riyals or 45.4 percent of the total." These data stem from the following link: http://www.reuters.com/article/qatar-budget-idUSL8N14532X20151216 (23/2/2018).

In light of this, Qatar can be seen as a progressive country in terms of its research culture and its effort to invest a lot in educating its citizens, in order for the latter to become tomorrow's leaders in their respective fields and to contribute towards the sustainability of the country. My experience working in this country for the past 7.5 years has shown me that education for Qatar means a coupling of teaching and research, in the sense that one feeds into the other, in order for both of them to have a society-based and problem-solving-oriented dimension. 
Along the lines of using teaching to facilitate research and to thus train students to design, conduct and employ their findings to improve their and their communities' lives, after doing a survey among my female undergraduate students on their needs and expectations from a Language and Gender course, we decided collectively with my students to have an assessment tool that not only measures students' performance in the course but it also, and perhaps most importantly, allows students to build up an impact on their communities and the society of Qatar via doing research. The project, which is called "lost and found voices paper", essentially gave students the opportunity to sit together, discuss and suggest practical and tangible solutions to the problems they face in their daily lives, including sexism.

\section{The Problem}

Sexism is discriminatory behaviour against women or men or any sort of gender categories, such as homosexual people or transgender people, on the basis of their sex. This behaviour can be linguistic, social or cultural (cf. Savigny 2014). From a Western perspective, meaning here from the point of view of Westerners and/or Arabs, who have been educated, lived and worked in the West for a long time, sexism is admittedly very evident in the Arab world either as "misogyny" (e.g. Eltahawy 2012), namely as hatred against women, or as "erasure" (Irvine \& Gal 2000:38) of women, namely the process by which "ideology renders some persons or activities (or sociolinguistic phenomena) invisible." In this particular case, it is women whose presence in and via language becomes mute.

Along the same lines of erasure, scholarship on Arabic language in English by Arabs has viewed sexism as women being "silent, in the sense that their presence is hardly felt in language, although the Arabic language has a clear system of masculine and feminine gender" (Al-Easa 2009:4-5). In this body of research, there seems to be controversy regarding the status of Arabic as a sexist language; on the one hand, it has been admitted that Arabic, which has grammatical gender contrary to English, is a highly sexist language; in fact, it has been characterised as "a masculine language not a feminine one" (Mahmoud 1993, cited in Al-Easa 2009:5; cf. Spender 1990), because there are a number of grammatical rules that foreground masculine over feminine forms; a striking example of such a rule is that when the subject of a sentence includes both males and females, the verb which is performed by that subject will be conjugated for the masculine. An example of this rule is found in the following example: al nisa' wa al rijal 
ya'amalun m'aa 'the women and the men work together'). For ease of reference, all Arabic texts and words have been transliterated in Latin script (Arabizi), according to Albirini (2016). In the aforementioned example, the prefix ya- of the verb is the masculine form, even though the verb's subject contains both women and men. A rule like this has been argued to reflect the social history of the Arabic language, which is a masculine one in authority, sovereignty, and in regulating and controlling the society (Mahmoud 1993, cited in Al-Easa 2009:5-6).

On the other hand, scholars, like, Eslami et al. (2015), have shown that Arabic has instances of sexism, including fixed expressions using the generic male form, even when they address women, such as the ritualistic formal greeting as salamu alaykum "may peace be upon you," but in general he argues in favour of the idea that Arabic is not sexist on the basis of grammatical and lexical/semantic evidence.

These contradicting perspectives provided the incentive for our classroom discussion on (linguistic) sexism and essentially they acted as the impetus for students' exploration of the topic in their papers. More specifically, in their "lost and found voices" papers on sexism they were asked not only to identify and document instances of linguistic sexism but also to suggest ways to tackle it in their societies.

What my experience in Qatar has shown me is that there is significant variation in terms of how women deal with this issue. It is usually the case that my Qatari female students are the ones, who refuse to have pictures taken of them in public spaces for the fear of being distributed in public. On the other hand, my Muslim students from other parts of the Arab world, especially from Egypt, the Levant area (Syria, Lebanon, Jordan, Palestine) and the Maghreb area (Morocco, Algeria, Tunisia, and Libya) tend to be more flexible. Apart from their country of origin significant factor in terms of their stance vis-a-vis their portrayal in pictures is also the type of their family, i.e. if it is religious or more secular. Obviously students from secular families do not object to their daughters having their pictures taken and posted in social media, such as Facebook and Instagram.

As it was observed by a Lebanese female student of mine, whom I have given the pseudonym Jumana, many women in the Arab world have been in situations, like at a doctor's clinic, where they need to give their husband's or their father's names in addition to their own, while male patients need only to give their mobile phone numbers, in order for the administrative assistants to be able to distinguish between people with the same name. Such practice, however, 
according to Jumana is not usually identified as sexism, simply because in her own words "it is something so pervasive that it has eventually become normal." Growing up, girls have been "socialised" to view themselves as "extensions of others" (Joseph 1993) which might be at the bottom of many sexist practices that manifest themselves through language (see also chapters in Hellinger \& Hadumod 2001).

Such controversial takes on what counts as sexism in the Arab world have given birth to what critical discourse analyst Norman Fairclough has identified as two different types of critique of sexism discourse: "normative" and "transcendental" critique (Fairclough 2015:12). Fairclough has talked about these two types in the context of the UK; however, due to their relevance to the Arab world context, these two terms are used in this paper as well. The former translates into a more logic-oriented critique that "identifies internal contradictions within the social reality, including those between what is supposed or said to happen and what actually does happen," while the latter goes outside the "social reality it is critiquing to find a measure or a standard against which reality can be evaluated and criticized" (e.g. religion) (ibid.)

In our discussions with students, these two types of critique were explained by me to them and they were used in classroom debates by students and by me. Unsurprisingly, students, who came from highly religious backgrounds and/or the ones that self-identified as religious tended to show preference for transcendental critique, while the rest, including me, favoured the normative one. It was agreed, after extensive negotiation, that the main form of sexism in the Arab world, according to the ones that thought that there is sexism in Arabic language anyway, is the erasure of women's presence in language through the prevalence of the generic "he" (cf. Graddol \& Swann 1989; Cameron 1992). Departing from this erasure of women at the linguistic level, gender inequalities in the Arab world, like elsewhere in the world (e.g. in the US, in many European countries or in Japan) constructed linguistically and discursively, were identified by my female students themselves as a real-world problem of human well-being for the simple reason that they have a negative influence on women's everyday life: e.g. the fact that women receive lower salaries than men, even though both sexes put the same amount of effort or work, the same number of hours on a daily basis, or the fact that in Saudi Arabia, as is widely known, women cannot travel unescorted by a man in their family or a chaperon, or even go to surgery without consent from a male relative. 


\section{Sexism in Education}

\subsection{Amthal}

In the past, before the establishment of formal education at schools, children not only in Qatar but in the whole Gulf area used to receive education from elder people, such as al mutawa (the teacher) or imam or even from their grandparents. These people used to offer comments on lots of social issues, ranging from how to run the household to how to deal with death. These commentaries were given in the form of proverbs, which are known as mathal (singular) or amthal (plural) in Arabic. Amthal are brief proverbs or statements reflecting popular beliefs and customs or attributed to religious tradition (Zuhur 2011:329). The amthal are passed from generation to generation, even nowadays. Most of these commentaries, however, were identified by my students as promoting sexual inequality. For me, this was an enlightening finding, given the pervasiveness of amthal in the everyday life of my Arab students; it was rewarding to see that they dealt with such mundane, for them, discourses through a critical thinking lens. This is important, especially in the Gulf countries, where the exercising and subsequent cultivation of critical thinking skills, at least as we know it in the West, is far from being the case. The vast majority of my students have graduated from governmental schools, which promote memorization instead of critical thinking. Hence, one of the big challenges faculty members, especially the ones trained in the West, are faced with include ways of teaching these students how to think for themselves and construct a solid argument.

The first example of sexism from the context of amthal, stemming from the paper of three students, whom I will call Maryam, Fatima and Noor, includes the following: Um Nasr ilsaan tauil wel hail gassir "Nasser's mother has a long tongue without power." According to the students, this commentary assigns women negative connotations, as the woman is referred to not through her actual name but her role as the mother of Nasr is foregrounded. In addition, a negative feature is assigned to her, which is the practice of talking at great length without actually saying anything important. Except for the fact that the name of that woman is not mentioned (see Bassiouney 2009:148-9 for the muting of female names in the Arab world), she is referred to as "the mother of Nasser," a sexist practice, in terms of its content it shows that women are treated

as chatterboxes with no actual power, seen here as the ability to take initiatives and to actively engage in practices. In other words, women talk too much and do not have control over what they say. It is more common to see a commentary with negative connotation about women. Even 
when the commentary has positive connotations about women there is sexism as well. For example, okht rjal "a sister of men" means that the woman talked about is strong, because supposedly she has male siblings.

On the other hand, commentaries assigned for men are mostly associated with positive connotations. An example of such a commentary includes the following: al baiz biad al rijal "the men hold on to all the wealth." This mathal shows that men have the power to control everything. By extension, what this commentary means, according to my students, is that men take things seriously, are competitive and hence can be better decision makers.

\subsection{Educational Assessment Activities}

In the case of assessment activities used in educational contexts, examples of sexism in MSA are abundant in midterm tests or common exams that are given (in Arabic-speaking) schools and universities. A lot of common exams that are usually prepared by people, who work at the Supreme Education Council (like in Qatar) or the Ministry of Education (like in Egypt) and are distributed to all schools, contain questions that have masculine pronouns as morphological affixes within the verbs addressing both female and male pupils. For example, the word ajib which means "answer the question (masc.)" or the word ikra which means "read (masc.)." Other, more elaborate, examples of two questions from a high school common exam include the following: aref (2nd sg. masc.) kolan men "define the following" and ma raeek (2nd sg. masc.) $f i$ al'abaara alatee tahtahaa khat. Dalel (2nd sg. masc.) min aluaqa' aladee na'eeshuhu alan "what is your opinion about the underlined sentences? Give examples from our real life." These questions are usually asked about a designated paragraph from a text, which is distributed to the students in the exam. Through these examples we can see how the female students recognise the fact that women already from the level of secondary education are erased completely in the language of exams, which nonetheless they need to take. It is indeed ironic that such language is used in educational assessment activities distributed to female only schools. In the State of Qatar all governmental schools are gender-segregated, resulting in boys' and girls' schools.

The second part of the research paper, which the students were asked to submit, included the suggestion of tangible and realistic ways, whereby sexism can be tackled. This aspect of the project did not yield the level of interesting and creative ideas I was hoping to elicit from them. The reason for this is most probably because the vast majority of my students searched on the 
Web for attempts that have been already made in the West to deal with sexism and they copied them in their papers without making the effort to adapt them to the standards and peculiarities of their native countries, and especially Qatar. A characteristic example to illustrate this is the inclusion of Gender Mainstreaming Strategy, which is a global strategy that promotes gender equality, established through the Platform for Action at the United Nations $4^{\text {th }}$ World Conference on Women in Beijing in 1995.

Without any further elaboration, the students suggesting the application of this strategy claimed that it would be beneficial for women, if it would be applied by government and media services in Qatar to eliminate sexism. My interpretation of such an approach based on my experience with the students is that they still feel reluctant to make suggestions, let alone to be proactive, in terms of policy making, exactly because so far they have not been encouraged to think for themselves and use their imagination to find ways to change the status quo of situations they do not like.

On the other hand, there were a number of students from Lebanon and Tunisia who tried to suggest something tailored to their societies' needs and they justified their claims. More specifically, it was suggested that "gender classes" be taught and introduced in the curriculum at the level of elementary schools. By doing that, it was claimed that children will be exposed to a variety of gendered practices at an early age, so they will hopefully develop a relaxed and flexible stance vis-à-vis them, and they will understand that "sex does not matter so much in terms of what gendered behaviour you choose to adopt," as my student Nouf put it. The students who are in favour of introducing gender classes are happily students, who major in education. In informal discussions, they told me that when they start working as teachers they will definitely try to persuade the principal of their school to allow them to teach this sort of class. For them, it is paramount that this type of education starts already from elementary school, because they realize that as adult university students, it is harder for them to detach from sexist behaviours simply because what they have come to realise as sexism is natural to the majority of Arabs, exactly because they have been taught this way, hence they consider instances of sexism as the norm.

Apart from outputs, there are also some important outcomes, which have started paving the way for dealing with sexism, at least in the context of $\mathrm{X}$ university. In the interest of anonymity, $\mathrm{X}$ is the name of the university, where this study has taken place. The most tangible example of an outcome yielded through this type of merging research with teaching is my 
students' effort to contribute to a non-sexist university. This effort was initiated by trying to abolish sexism from all official documents of the university. Notable is here the fact that some of the best graduates from our department, exactly due to their good command of English, are usually hired by the university services to work as translators and/or editors. In fact, some of my students who have taken the Language and Gender course, have been hired as translators and editors in the University International Students Office. The more enthusiastic ones, who have been top achievers in their respective classes, keep telling me how grateful they are for taking this course and that they have realised how powerful language is in terms of making the university (and, by expansion, our society) much more inclusive and fair.

Aysha was hired by the X University Student Centre as an editor in January 2014. In a recent discussion I had with her, she brought to my attention the fact that the link that discusses "The International Students Section Policies ${ }^{1 "}$ in English included an extensive use of the generic "he," but after her intervention, the use of generic "he" has been significantly reduced. I have checked the link myself, and I have found that there are still instances of use of the generic "he," even though $70 \%$ of the student population of the university are indeed females, but I hope that sexism will be soon eliminated from that link.

Along the same lines, but much more successfully, I have come to realise that the $\mathrm{X}$ University Undergraduate Student Catalogue ${ }^{2}$ has started using a gender neutral language for the past three years now, even though five years ago the very same document used to favour the generic "he."

Similarly, women have started becoming more visible semiotically speaking in the same document. A comparison between the Undergraduate Catalogue of academic years 2011-2012 and 2013-2014 found in Table 1 shows that there is an increase in the number of pictures of women:

\begin{tabular}{|l|l|l|}
\hline & $\begin{array}{l}\text { Undergraduate } \\
\text { Catalogue 2011-2012 }\end{array}$ & $\begin{array}{l}\text { Undergraduate Catalogue 2013- } \\
2014\end{array}$ \\
\hline Number of pictures with women & 5 & 9 \\
\hline
\end{tabular}

\footnotetext{
${ }^{1}$ http://www.qu.edu.qa/students/services/is/index.php (23/2/2018)

${ }^{2}$ http://www.qu.edu.qa/students/catalog.php (23/2/2018)
} 


\begin{tabular}{|l|l|l|}
\hline Number of pictures with men & 7 & 6 \\
\hline Number of pictures with both & 0 & 0 \\
\hline Overall number & 12 & 15 \\
\hline
\end{tabular}

Table 1: Number of pictures of women and men in the $X$ University Undergraduate Catalogues of academic years 2011-2012 and 2013-2014

Apart from the quantitative difference, there is also a qualitative difference in terms of the types of pictures that have started being used in the Undergraduate Catalogue; the Undergraduate Catalogues of the academic years 2012-2013 and 2013-2014 have full frontal pictures of women, as opposed to pictures depicting blurred female faces and/or pictures taken from a distance from the photographed women. Examples of the full frontal pictures included in the Catalogues are found below: 


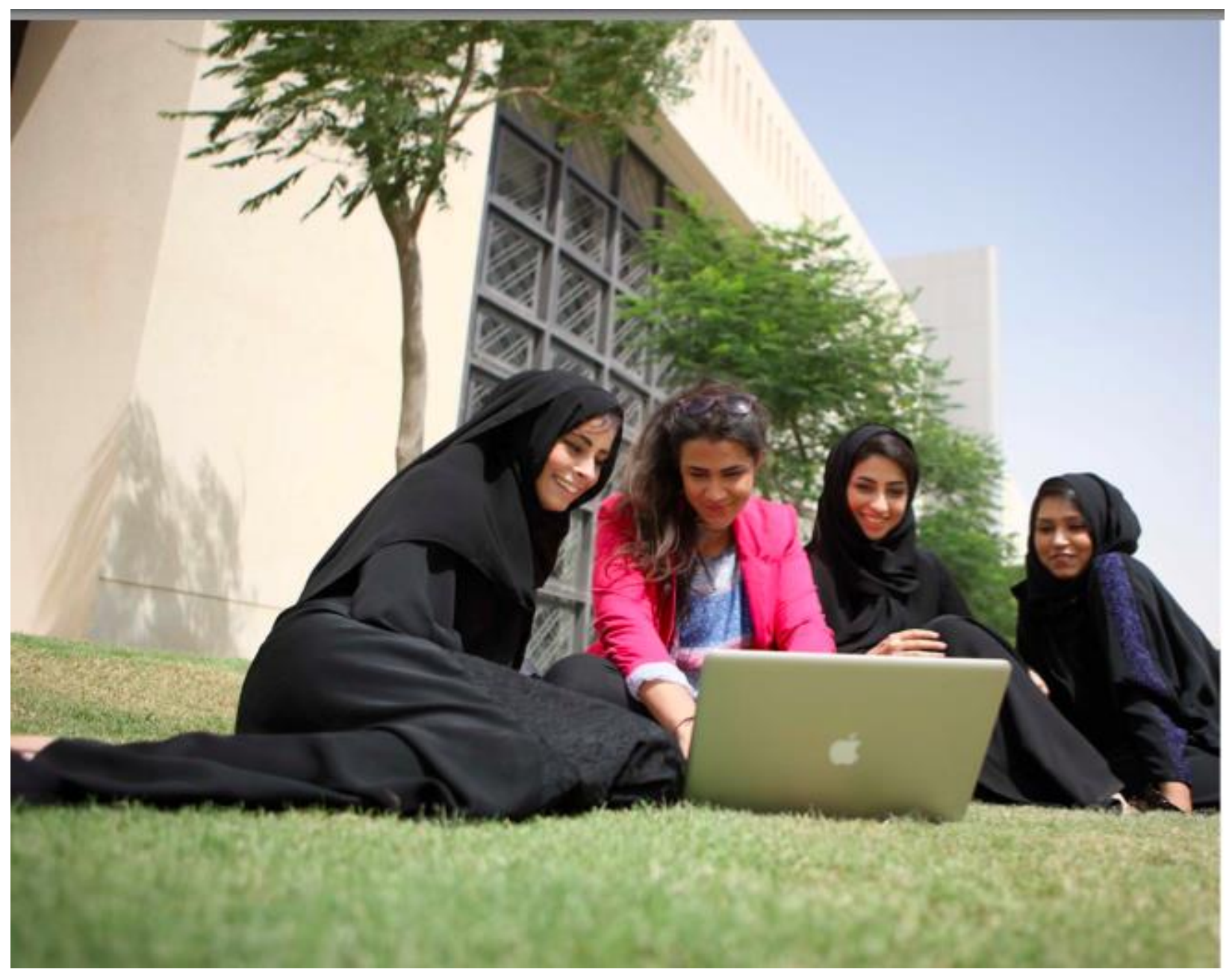

Picture 1: Female students in $\mathrm{X}$ University 1 (outdoor picture). Source: $\mathrm{X}$ University Undergraduate Catalogue 2013-2014, p. 12 


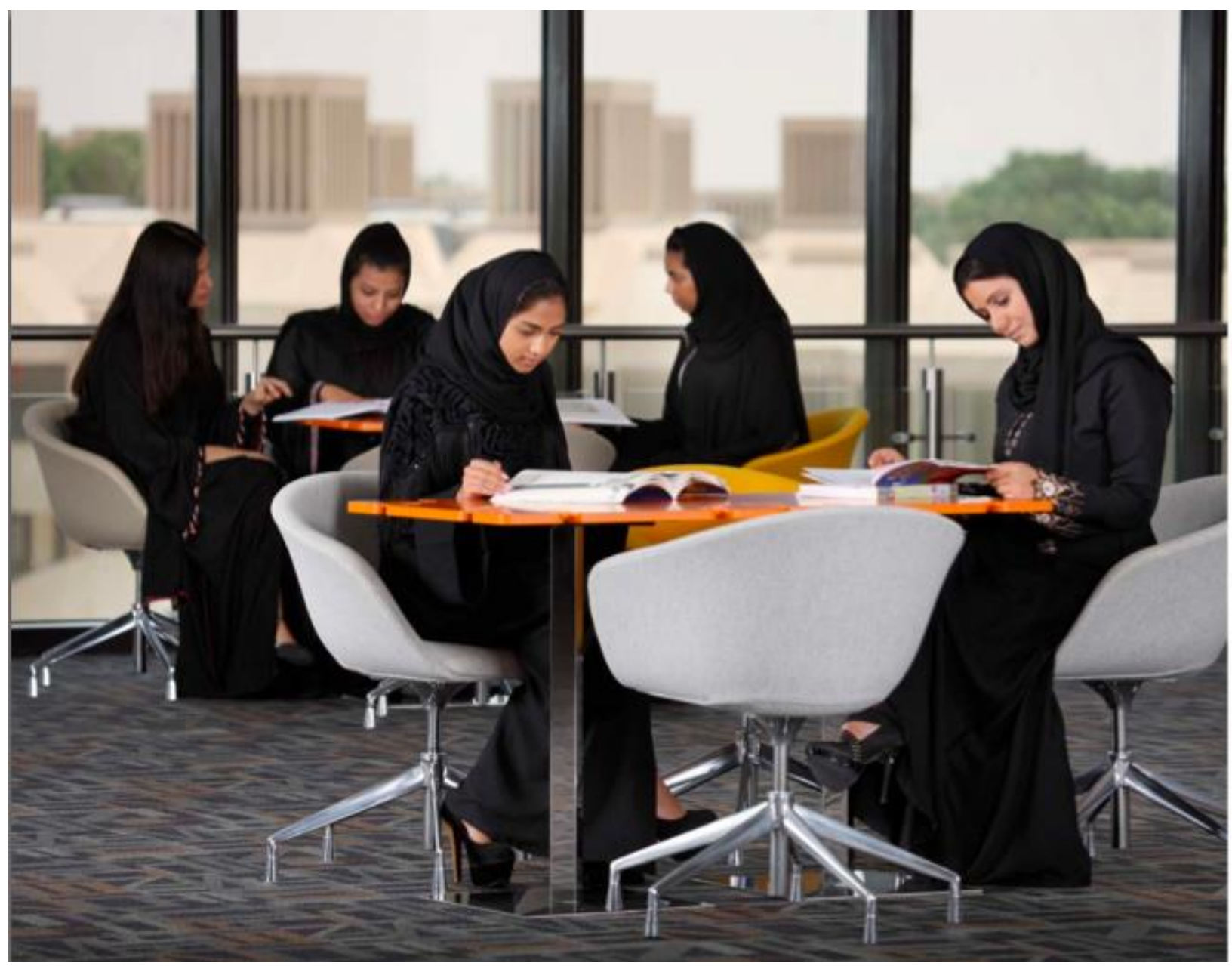

Picture 2: Female students at X University (indoor picture). Source: X University Undergraduate Catalogue 2013-2014, p. 44

4 of my former students, who have attended Language and Gender and have done research on sexism, belong to the editorial team in charge of putting together this document. Obviously, I am not suggesting that this change is solely due to the fact that some of the editors of these very important documents have been exposed to the pitfalls of sexism via the research they undertook in my course; I need to emphasize that it is usually the case in X University that in all of these services, especially the ones, which produce widely circulated official documents, there are usually native speakers of English, who coordinate the editorial and/or translation team members. However, I would argue that if a former student has dealt with sexism from an empirical perspective, like my students, it is highly possible that their editing is conscious and they realise 
how important their role is in the compilation and presentation of the values and ideologies of an institution, such as X University.

Finally, regarding the outcomes of this project, my Lebanese student Jumana reported in the last lecture of my Spring 2013 Language and Gender course that she always tries to bring up the issue of sexism in her parent-teacher meetings and in her individual discussions with the parents of the children, who are schoolmates with her son, so as to sensitize parents to teach their children how to use a non-sexist language. The reason for this is because she considers sexism as a cultural problem, so she believes that "if you make fuss about it" in mundane meetings, "lay people will be able to detect it and act against it not just academics."

In my opinion, grassroots initiatives like this, which do not have an official form but are rather impromptu, can be seen as strong indicators of the impact sociolinguistic research on language and gender can have on people's everyday life, in the sense that they are direct, honest,

non-threatening and hence highly likely to get their message through among many people, who are responsible for the education of the next generations. So, in this way the impact of research could be seen as standing a good chance of lasting in the long run.

My expectations from this project were higher than just the production of papers on behalf of students. I would very much have liked to see them organizing a campaign against sexism translating into distributing to their fellow students brochures about sexism and talking about it extensively in social media, like Twitter, Facebook and Instagram, which are their favourite communication arenas. All the same, this was not the case, at least to my knowledge, maybe because many students still view the issue of sexism as an academic rather than a social issue, which is not of interest to them after the end of the course.

\section{Reflections}

The "Lost and hopefully found voices" teaching research project that I initiated in my Language and Gender courses taught in Fall 2011 and Spring 2013 semesters respectively, aimed at using sociolinguistic research as a vehicle for empowering women. This was done in the context of a discussion of sexism in the Arab world and the data that were used in the project were primarily in Arabic (both in MSA and in various Arabic dialects) as well as in English (the variety used by native speakers of Arabic). Overall, I would say that despite its challenging milestones that both the students and I had to face in the process, it was a rewarding experience 
for everybody involved, in the sense that the seeds of using sociolinguistic research for the benefit of the Arab world have been sown.

In terms of its contribution to gender-related sociolinguistic theory this project can be seen as an attempt to offer a suggestion on how to theorise the positionality of sociolinguistic professionals in relation to issues and contexts they address (Wee 2016:333). As a Westerner, the first problem I had to deal with in the class was how to initiate the multiple dimensions of sexism for classroom discussion without imposing them on my students. In other words, I had to balance between my teaching duties (i.e. sexism was one of the major topics in my syllabus) and my subconscious ethnographic role as a researcher and observer of the various Muslim-based cultures represented in the class. This dilemma is known as "researching with" instead of "researching on" or "researching for" social actors (Cameron et al. 1992). Achieving researching with your students essentially means that as a researcher you minimize the temptation of acting as an authoritative expert creating a hierarchy between yourself and students, which in turn might jeopardise research on the basis of lack of mutual trust.

Women in Qatar have started (re)finding their voices, something which is evident through the presence in public media of powerful Qatari women, who are leaders in their fields and, hence, they act as role models, not only for Qatari women, but also for many women, who reside in Qatar. Such examples include, starting with the most prominent one, Sheikha Moza Al Misned, the second wife of the Father Emir, HH Sheikh Hamad bin Khalifa Al Thani, who is also the mother of the current Emir of the State of Qatar, HH Sheikh Tamim bin Hamad bin Khalifa Al Thani. Sheikha Moza is the Chairperson of Qatar Foundation, an important educational institution, which endorses research, culture and education, not only in Qatar but all over the world. Sheikha Moza has been very productive in terms of encouraging women in the Middle East to get educated, and she is also the recipient of multiple accolades and awards due to her extensive philanthropic activities. Likewise, her daughter, HE Sheikha Mayassa bint Hamad Al Thani, is the Chairperson of Qatar Museums Authority, who through her activity has put Qatar on the cultural map. Finally, Professor Sheikha Abdulla Al Misnad, the former President of Qatar University, is a woman with extensive activity around the issue of educating women in Qatar. It is primarily because of women like these that Qatar has put education and culture in such as prominent position, something which is far from being the case in many countries in the Western world. 
It is hoped that through doing sociolinguistic research, female students in particular will not only (re)find their lost voices but they will also establish it in both public and private spheres in Qatar and in the world. In this way, they will put themselves of the map, just like the aforementioned women have already done, and they will strive for equality and justice, two important features that can contribute towards the sustainability of Qatar in the long run, which is the ultimate goal found in Qatar Vision 2030, the sociopolitical and financial compass of the country.

\section{References:}

Albirini, Abdulkafi. 2016. Modern Arabic Sociolinguistics: Diglossia, Variation, Codeswitching, Attitudes and Identity. London/New York: Routledge.

Al-Easa, Noor S. 2009. "Sexist Language in Arabic: The Case of Qatar University Academic and Administrative Staff." Journal of the Documentation and Humanities Research Center 8:1-19. [Online] Available: http://hdl.handle.net/10576/8402 [Accessed 2018, February 23].

Bassiouney, Reem. 2009. Arabic Sociolinguistics. Topics in Diglossia, Gender, Identity, and Politics. Washington, DC: Georgetown University Press.

Cameron, Deborah. 1992. Feminism and Linguistic Theory. Basingstoke: Macmillan.

Cameron, Deborah, Frazer, Elizabeth, Harvey, Penelope, Rampton, Ben, and Richardson, Kay. 1992. (Eds.). Researching Languages: Issues of Power and Method. London: Longman.

Eltahawi, Mona. 2012. "Why Do They Hate Us? The Real War on Women is in the Middle East" [Online]. Available: http://www.foreignpolicy.com/articles/2012/04/23/why_do_they_hate_us [Accessed 2018, February 23].

Eslami, Zohreh R., Sonnenburg, Sunni, Ko, Wei-Hong, Hasan, Fatma, and Tong, Fuhui. 2015. "Gender Stereotyping and Linguistic Sexism in Qatari Teaching Materials" in Gender Representations in Learning Materials in an International Context. Mustapha Abolaji and Sara Mills (Eds.). New York: Taylor \& Francis, pp. 86-103.

Fairclough, Norman. 2015. Language and Power. Third Edition. London: Routledge. Graddol, David, and Swann, Will. 1989. Gender Voices. Oxford: Blackwell.

Hellinger, Marlis, and Bussman, Hadumod (Eds.). 2001. Gender across Languages: The Linguistic Representation of Women and Men. IMPACT: Studies in Language and Society, vol. 9.

Irvine, Judith and Susan Gal. 2000. "Language Ideology and Linguistic Differentiation" in Regimes of Language: Ideologies, Polities and Identities. Paul Kroskrity (Ed.). Santa Fe, NM: School of American Research Press, pp. 35-83.

Joseph, Suad. 1993. "Gender and Relationality among Arab Families in Lebanon.” Feminist Studies 19(3):465-486.

Lawson, Robert and Sayers, David. 2016a. “Where We're Going, We Don’t Need Roads. The Past, Present, and 
Future of Impact" in Sociolinguistic Research: Applications and Impact. Robert Lawson and

David Sayers (Eds.). London/New York: Routledge, pp. 7-22.

Lawson, Robert and Sayers, David. (Eds.). 2016b. Sociolinguistic Research: Applications and Impact.

London/New York: Routledge.

Savigny, Heather. 2014. "Women, Know Your Limits: Cultural Sexism in Academia" Gender and Education

26(7):794-809. [Online]. Available:https://www.tandfonline.com/doi/abs/10.1080/09540253.2014.970977

[Accessed 2018, February 23].

Spender, Dale. 1990 (1980). Man-Made Language. Second Edition. London: Pandora.

Wee, Lionel. 2016. “Are There Zombies in Language Policy? Theoretical Interventions and the Continued

Vitality of (Apparently) Defunct Concepts" in Sociolinguistics. Theoretical Debates. Nikolas Coupland

(Ed.). Cambridge: Cambridge University Press, pp. 331-348.

Zuhur, Sherifa. 2011. Middle East in Focus. Saudi Arabia. Santa Barbara, CA/Denver, Oxford, UK: Abc-Clio.

\section{Other Online Sources:}

Prominent women in Qatar

“Sheikha Moza’s site” Available: http://www.mozabintnasser.qa/en/Pages/default.aspx [Accessed 2018, February 23].

"Sheikha Mayassa's site" Available: http://www.ted.com/speakers/sheikha_al_mayassa [Accessed 2018, February 23].

"Professor Sheikha Al Misnad's site" Available: http://www.qu.edu.qa/offices/president/biography.php [Accessed 2018, February 23].

Prominent men in Qatar (empowering women)

"HH the Emir, Sheikh Tamim's site" Available: http://en.wikipedia.org/wiki/Tamim_bin_Hamad_Al_Thani [Accessed 2018, February 23].

"HH the Father Emir, Sheikh Hamad's site" Available: http://en.wikipedia.org/wiki/Hamad_bin_Khalifa_Al_Thani [Accessed 2018, February 23]. 